\title{
Combined effects of interleukin-1 $\beta$ and cyclic stretching on metalloproteinase expression in corneal fibroblasts in vitro
}

\author{
Pengfei Feng ${ }^{1}$, Xiaona Li $i^{*}$, Weiyi Chen ${ }^{1 *}$, Chengxing Liư ${ }^{3}$, Shuo Rong ${ }^{1}$, Xiaojun Wang ${ }^{2}$ and Genlai Du ${ }^{1}$
}

\author{
*Correspondence: \\ lixiaona@tyut.edu.cn; \\ chenweiyi211@163.com \\ 1 Institute of Applied \\ Mechanics and Biomedical \\ Engineering, Taiyuan \\ University of Technology, \\ Taiyuan 030024, China \\ Full list of author information \\ is available at the end of the \\ article
}

\begin{abstract}
Background: Corneal tensile strain increases if the cornea becomes thin or if intraocular pressure increases. However, the effects of mechanical stress on extracellular matrix $(E C M)$ remodelling in the corneal repair process and the corneal anomalies are unknown.

Methods: In this study, the combined effects of interleukin-1 $\beta$ (IL-1 $\beta$ ) on matrix metalloproteinases (MMPs) in corneal fibroblasts under cyclic stretching were investigated in vitro. Cultured rabbit corneal fibroblasts were subjected to 5, 10 or $15 \%$ cyclic equibiaxial stretching at $0.1 \mathrm{~Hz}$ for $36 \mathrm{~h}$ in the presence of IL-1 $\beta$. Conditioned medium was harvested for the analysis of MMP2 and MMP9 protein production using the gelatin zymography and western blot techniques.

Results and conclusions: Cyclic equibiaxial stretching changed the cell morphology by increasing the contractility of F-actin fibres. IL-1 $\beta$ alone induced the expression of MMP9 and increased the production of MMP2, and $5 \%$ stretching alone decreased the production of MMP2, which indicates that a low stretching magnitude can reduce ECM degradation. In the presence of IL-1 $\beta, 5$ and $10 \%$ stretching increased the production of MMP2, whereas $15 \%$ stretching increased the production of MMP9. These results indicate that MMP expression is enhanced by cyclic mechanical stimulation in the presence of IL-1 $\beta$, which is expected to contribute to corneal ECM degradation, leading to the development of post-refractive surgery keratectasia.
\end{abstract}

Keywords: Cyclic stretching, Interleukin-1 $\beta$, Corneal fibroblasts, Matrix metalloproteinases

\section{Background}

Corneal refractive surgery is one of the most widely used methods for the correction of refractive errors [1]. The distribution of stress or strain in the cornea under intraocular pressure (IOP) was investigated. Animal experiments [2-4] and finite element simulation $[5,6]$ show that corneal membrane stress or strain increases after keratorefractive surgery. As a load-bearing tissue, the cornea is mainly subjected to biaxial tensile stress because of IOP in vivo [7]. IOP fluctuates during the occurrence of hypertension and the change in head positions or sleeping postures [8-10]. The combination of tight eye closure and forceful rubbing may increase the IOP to more than 10 times the normal levels, perhaps even higher [11]. The same type of eye rubbing activity following 
keratorefractive surgery may have a greater chance of causing an adverse response, including ectasia, in a thinner or otherwise more susceptible cornea [11].

Interleukin-1 $\beta$ (IL-1 $\beta$ ), a proinflammatory cytokine, is constitutively expressed in the corneal epithelium [12]. After injury, IL-1 $\beta$ is released from the epithelium into the tear and the corneal stroma as a master modulator of the corneal wound healing cascade [13]. Proinflammatory cytokines are also involved in the pathogenesis of dry eye disease $[14,15]$, which is one of the most common complications after keratorefractive surgery [16].

Matrix metalloproteinases (MMPs) are a family of proteinases that initiate the degradation of collagen and other extracellular matrix components [17]. Two gelatinases, namely, $72 \mathrm{kDa}$ gelatinase A (MMP2) and $92 \mathrm{kDa}$ gelatinase B (MMP9), are the primary matrix-degrading enzymes that are initially secreted as proenzymes (Pro-MMP2 and Pro-MMP9) [18]. MMP2 and MMP9 play important roles in corneal wound healing after refractive surgery $[19,20]$, corneal ulceration [21], post-refractive surgery keratectasia [22-24], and the pathogenesis of dry eye disease [14].

In vivo, most living cells are exposed to a variety of biomechanical forces [25]. Mechanical stimulation is involved in the regulation of MMPs in some ocular tissues, such as sclera [17, 26, 27], trabecular meshwork [28] and lamina cribrosa cells [29]. Corneal fibroblasts have been demonstrated to respond actively to local tension changes in the ECM [30], and fibroblasts are a major type of mechanoresponsive cell [31]. Our previous work showed that large-magnitude stretching alone increased the protein expression of MMP2 in rabbit corneal fibroblasts at $24 \mathrm{~h}$ in an ERK-dependent manner [32].

We speculate that the increased strain caused by thinning of the cornea or the abnormally high IOP induces changes in ECM metabolism and alters the biomechanical properties of the cornea under the action of proinflammatory cytokines. In this study, we will focus on the combined effects of cyclic stretching and IL-1 $\beta$ on the production of MMP2 and MMP9 by rabbit corneal fibroblasts to investigate the role of mechanical stimulation in corneal ECM synthesis.

\section{Methods}

\section{Preparation of corneal fibroblasts}

New Zealand White rabbits were obtained from Shanxi Medical University $(n=6)$. Animals were anaesthetised with ether and killed using the air embolism method. Corneal keratocytes were immediately isolated and maintained as described previously [33]. In brief, the epithelial sheet and endothelial layer of the cornea were removed mechanically and the remaining tissue was treated with type II collagenase $(2 \mathrm{mg} / \mathrm{mL}$, in DMEM/F12) (Thermo Fisher Scientific, USA) at $37{ }^{\circ} \mathrm{C}$ until a single-cell suspension was obtained. Isolated corneal keratocytes were cultured in DMEM/F12 medium supplemented with $10 \%$ foetal bovine serum (FBS; Gibco, USA) and maintained at $37{ }^{\circ} \mathrm{C}$ in a humidified atmosphere of $5 \% \mathrm{CO}_{2}$ in air (cultured keratocytes will be referred to as corneal fibroblasts if they are cultured in serum) [12]. All of the experiments were conducted on cells between the third and fifth passage. 


\section{Cyclic equibiaxial stretching and IL-1 $\beta$ treatment on corneal fibroblasts}

Corneal fibroblasts were seeded on six-well Bioflex ${ }^{\circledR}$ plates (Flexcell Int. Corp., Hillsborough, NC, USA) with flexible bottoms coated with type I collagen. When the cell confluency reached $70 \%$, the medium was removed and replaced with DMEM/F12 medium containing $1 \%$ FBS and recombinant human IL-1 $\beta(0,0.2,0.4$ and $0.8 \mathrm{ng} / \mathrm{mL})$. Then, the cells were subjected to a mechanical strain of downward deformation by a computercontrolled vacuum using a Flexcell ${ }^{\circledR}$ Tension Plus ${ }^{\mathrm{TM}}$ FX- $4000^{\mathrm{TM}}$ system (Flexcell Int. Corp., Hillsborough, NC, USA) with an elongation rate of 5, 10 or $15 \%$ that was alternatively applied $(0.1 \mathrm{~Hz}, 36 \mathrm{~h}$, sine waveform).

The cell culture supernatants were collected at $36 \mathrm{~h}$ as protein samples for zymography or western blot analysis. The protein concentration was measured using BCA kit (Applygen Technologies Inc., Beijing, China).

\section{Fluorescence staining and confocal microscopy}

After $36 \mathrm{~h}$ of cyclic equibiaxial stretching $(5,10$ and $15 \%$ at $0.1 \mathrm{~Hz})$, cells were washed twice in phosphate-buffered saline (PBS) and fixed in $4 \%$ paraformaldehyde for $30 \mathrm{~min}$. Then, the cells were permeabilised for another 10 min with $0.5 \%$ Triton-X 100 in PBS. Cells were incubated with rhodamine B (Sigma, USA) for $30 \mathrm{~min}$ to stain the F-actin filaments. The cell nucleus was stained with 4', 6-diamidino-2-phenylindole (DAPI) diluted in PBS 1:20 for 10 min. Finally, fluorescence images were collected using an Olympus FV1000 confocal microscope.

\section{Gelatin zymography}

Gelatin zymography was used to analyse the relative concentrations of MMP2 and MMP9 secreted into the cell culture medium using a previously reported method [34]. In brief, each protein sample containing the same quantity of protein $(10 \mu \mathrm{g})$ was separated by $8 \%$ SDS-PAGE containing $0.1 \%$ gelatin. The gels were washed in twice $2.5 \%$ Triton-X 100 for $45 \mathrm{~min}$ and incubated in renaturing buffer at $37{ }^{\circ} \mathrm{C}$ for $42 \mathrm{~h}$. The gels were stained with $0.05 \%$ coomassie blue for approximately $2 \mathrm{~h}$ and were destained until bands were clearly visible. The gels were scanned, and the band intensities were quantitated using the Image Pro Plus 5.1 software (Medium Cybernetics Inc., Bethesda, MD, USA).

\section{Western blot}

Pre-stained markers and protein samples with equal amounts of total protein were separated by electrophoresis on $8 \%$ SDS-PAGE gels and transferred to polyvinylidene difluoride membranes (Millipore, USA). The membranes were blocked with TBST containing $5 \%$ non-fat milk. The procedure was followed by overnight incubation with a monoclonal antibody to MMP2 (1:1000) or MMP9 (1:500; Abcam, UK) at $4{ }^{\circ} \mathrm{C}$, six washes with $0.01 \%$ Tween-TBS buffer, and a $2 \mathrm{~h}$ incubation with a secondary antibody (anti-mouse HRP-linked, 1:7000; Abcam, UK). GAPDH (1:100; Boster, China) was used as control for equal protein loading. The band intensities were quantitated using the Image Pro Plus 5.1 software. 


\section{Statistical analysis}

All of the data from three independent experiments are presented as the mean \pm standard deviation. Statistical analysis was conduted using one-way ANOVA followed by a post hoc Tukey's test or using a Student's $t$ test to compare the experiments between only two groups. A value of $\mathrm{p}<0.05$ was considered significant.

\section{Results}

\section{Cyclic equibiaxial stretching changed the cell morphology of corneal fibroblasts}

After cyclic equibiaxial stretching, F-actin and nuclei were stained with rhodamine B and DAPI, respectively, to analyse the cell morphology. Confocal microscopy of actin filaments showed that cells under stretching or non-stretching had a random fibre orientation and had rounded cell bodies with extensions in multiple directions. Cyclic stretching increased the contractility of F-actin fibres at large magnitude. The effects of cyclic stretching on the alignment of actin fibres are shown in Fig. 1.

\section{IL-1 $\beta$ increased Pro-MMP2 and induced Pro-MMP9 secretion by corneal fibroblasts}

Pro-MMP2 was detected in the supernatant of cells with different treatments $(0,0.2,0.4$ and $0.8 \mathrm{ng} / \mathrm{mL}$ ). Pro-MMP2 produced by cells treated with 0.4 and $0.8 \mathrm{ng} / \mathrm{mL} \mathrm{IL}-1 \beta$ are
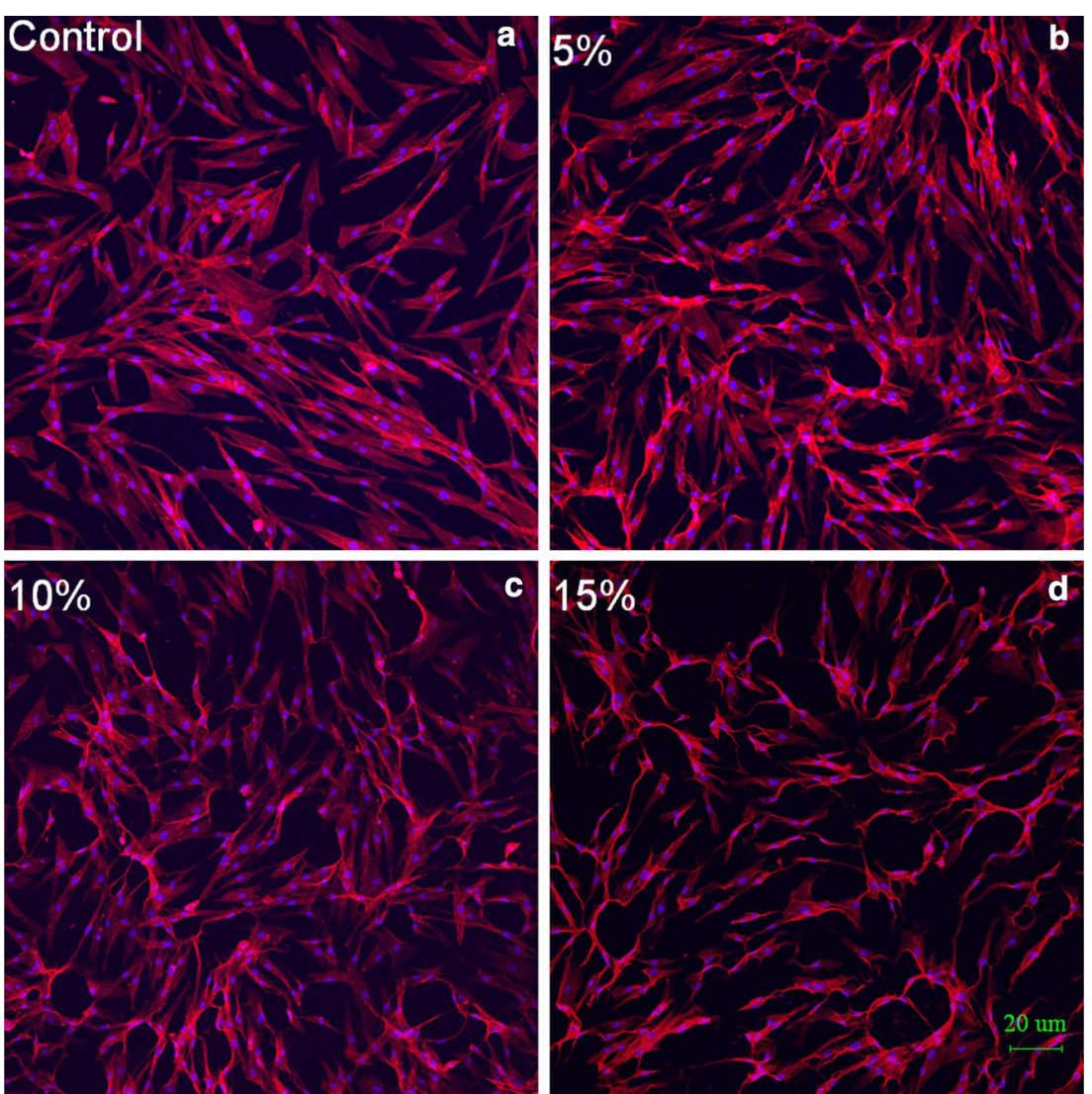

Fig. 1 The effects of cyclic stretching on cell morphology are shown. F-actin and nuclei of the cells were stained with rhodamine B and DAPI. a The cells were in the static condition. $\mathbf{b}-\mathbf{d}$ The cells were exposed to cyclic stretching for 5, 10 and $15 \%$ respectively. Red F-actin; Blue cell nuclei 
significantly higher $(\mathrm{p}=0.002$ and $\mathrm{p}=0.000$, respectively) than cells treated with $0 \mathrm{ng} /$ mL IL-1 $\beta$ (Fig. $2 *$ ). However, Pro-MMP9 was undetectable in the conditioned medium harvested from cultures in the absence of IL-1 $\beta$. IL-1 $\beta$ induced the expression of ProMMP9 and increased the production of Pro-MMP9 at $0.4 \mathrm{or} 0.8 \mathrm{ng} / \mathrm{mL}$ compared with $0.2 \mathrm{ng} / \mathrm{mL}\left(\mathrm{p}=0.033\right.$ and $\mathrm{p}=0.000$, respectively) (Fig. $\left.4^{*}\right)$.

\section{Cyclic stretching alone had a bidirectional effect on Pro-MMP2 and further increased Pro-MMP2 and Pro-MMP9 in the presence of IL-1 $\beta$}

After $36 \mathrm{~h}$ of cyclic equibiaxial stretching, Pro-MMP2 and Pro-MMP9 in the cell supernatant were determined. Statistical analysis of Pro-MMP2 and Pro-MMP9 was conducted to compare the 'stretched' and 'non-stretched' groups (static control). The results showed that $5 \%$ stretching decreased the expression of Pro-MMP2 $(\mathrm{p}=0.03)$, whereas 10 and $15 \%$ stretching increased the expression of Pro-MMP2 in the absence of IL- $1 \beta$ (Figs. 2, 3). In the presence of IL-1 $\beta, 5 \%$ stretching exhibited a significant increase in the expression of Pro-MMP2 compared with the corresponding static control. With $10 \%$ cyclic stretching, Pro-MMP2 was statistically increased at 0.2 and $0.4 \mathrm{ng} / \mathrm{mL}$, but not at $0.8 \mathrm{ng} / \mathrm{mL} \mathrm{IL}-1 \beta$ treatment. Compared with the static control, $15 \%$ stretching did not significantly change the expression of Pro-MMP2 by corneal fibroblasts receiving IL- $1 \beta$ treatment (Figs. 2, 3).

In the absence of IL-1 $\beta$, Pro-MMP9 was still undetectable under cyclic stretching with any of the three elongation rates (Figs. 4, 5). In the presence of IL-1 $\beta$, the expression of Pro-MMP9 was significantly upregulated in the $15 \%$ stretching group (0.2, 0.4 and

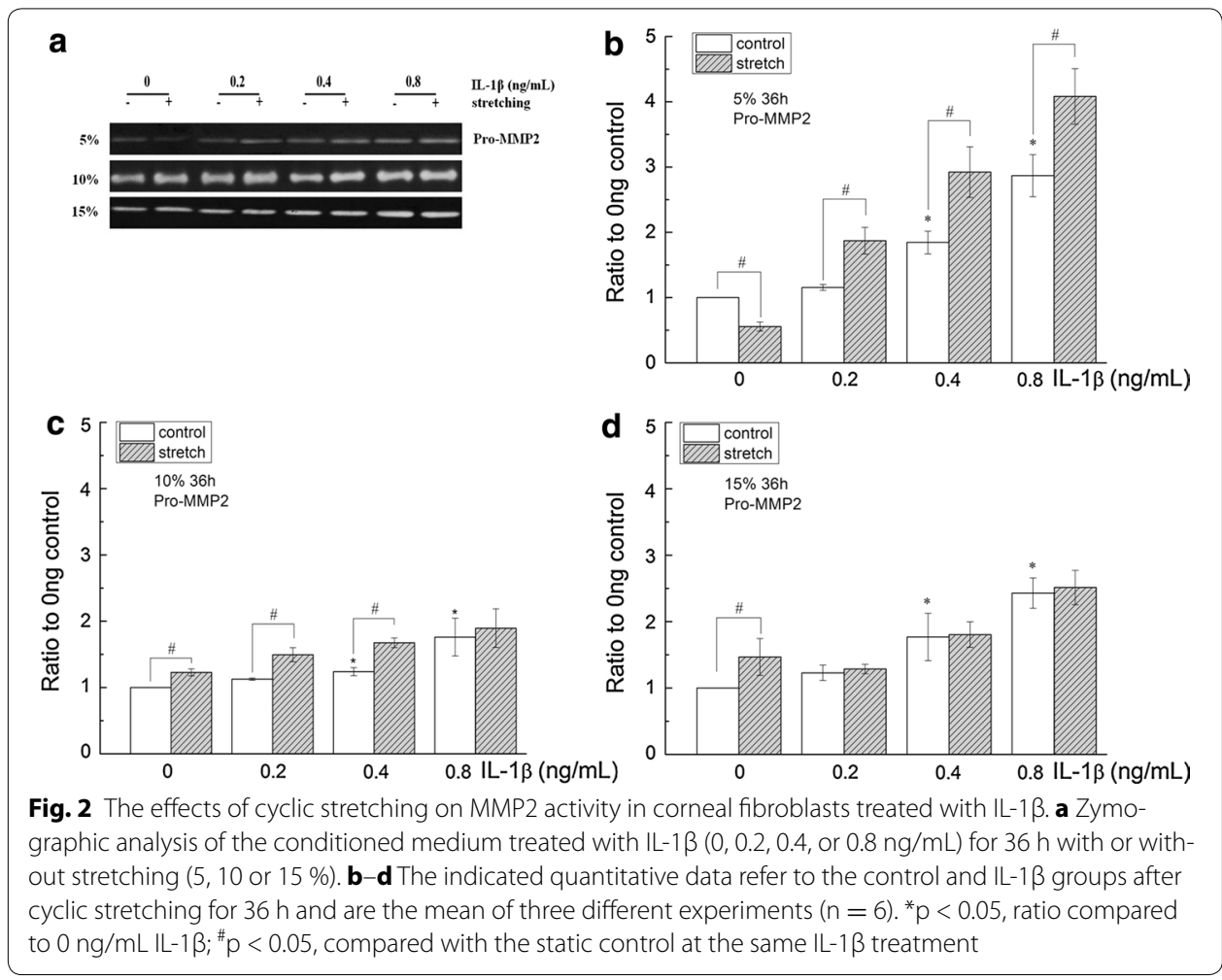


a
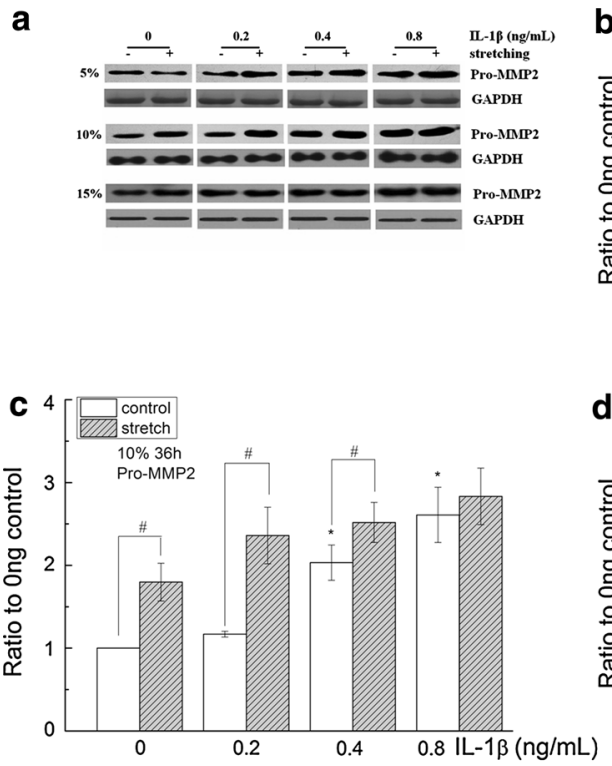

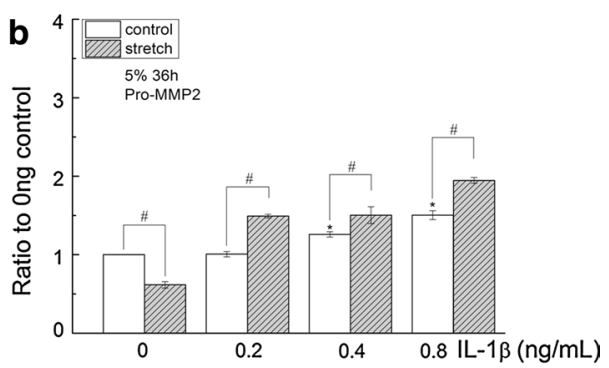

d $4 \longdiv { \square \text { control } }$

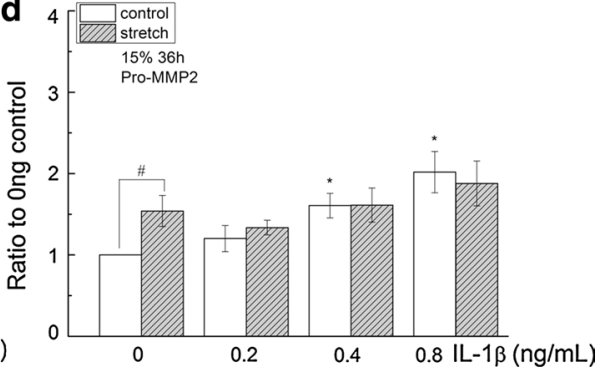

Fig. 3 The effects of cyclic stretching and IL-1 $\beta$ on MMP2 activity in corneal fibroblasts. MMP2 was detected by western blot (a) and quantified by densitometry $(\mathbf{b}-\mathbf{d})$. The indicated quantitative data are the mean of three different experiments $(n=6)$. ${ }^{*} p<0.05$, ratio compared to $0 \mathrm{ng} / \mathrm{mL} \mathrm{IL}-1 \beta ;{ }^{*} \mathrm{p}<0.05$, compared with the static control at the same IL-1 $\beta$ treatment
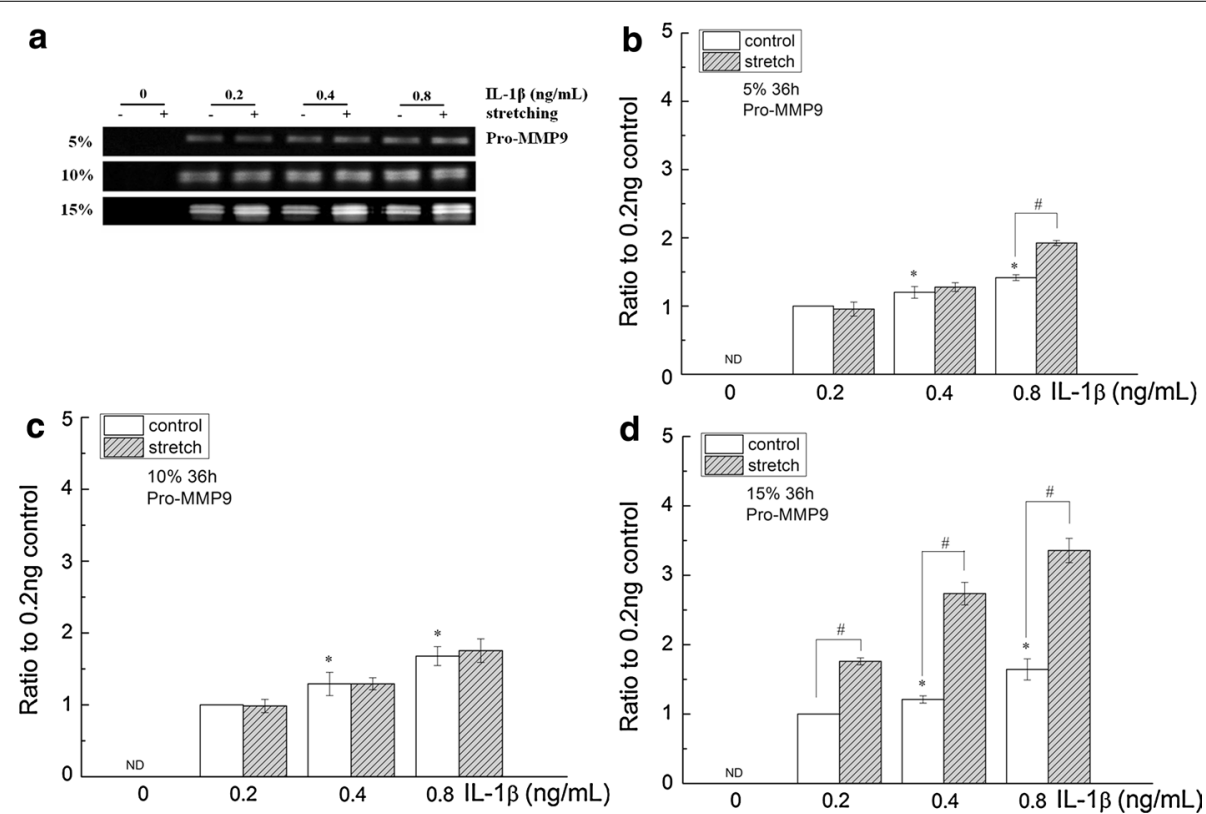

Fig. 4 The effects of cyclic stretching on MMP9 activity in corneal fibroblasts treated with IL-1 $\beta$. a Zymographic analysis of the conditioned medium treated with $I L-1 \beta(0,0.2,0.4$ or $0.8 \mathrm{ng} / \mathrm{mL})$ for $36 \mathrm{~h}$ with or without stretching $(5,10$ or $15 \%)$. b-d The indicated quantitative data refer to the control and IL-1 $\beta$ groups after cyclic stretching for $36 \mathrm{~h}$ and are the mean of three different experiments $(n=6)$. ND not detected; ${ }^{*} p<0.05$, ratio compared to $0.2 \mathrm{ng} / \mathrm{mL} I \mathrm{~L}-1 \beta ;{ }^{*} \mathrm{p}<0.05$, compared with the static control at the same IL-1 $\beta$ treatment 

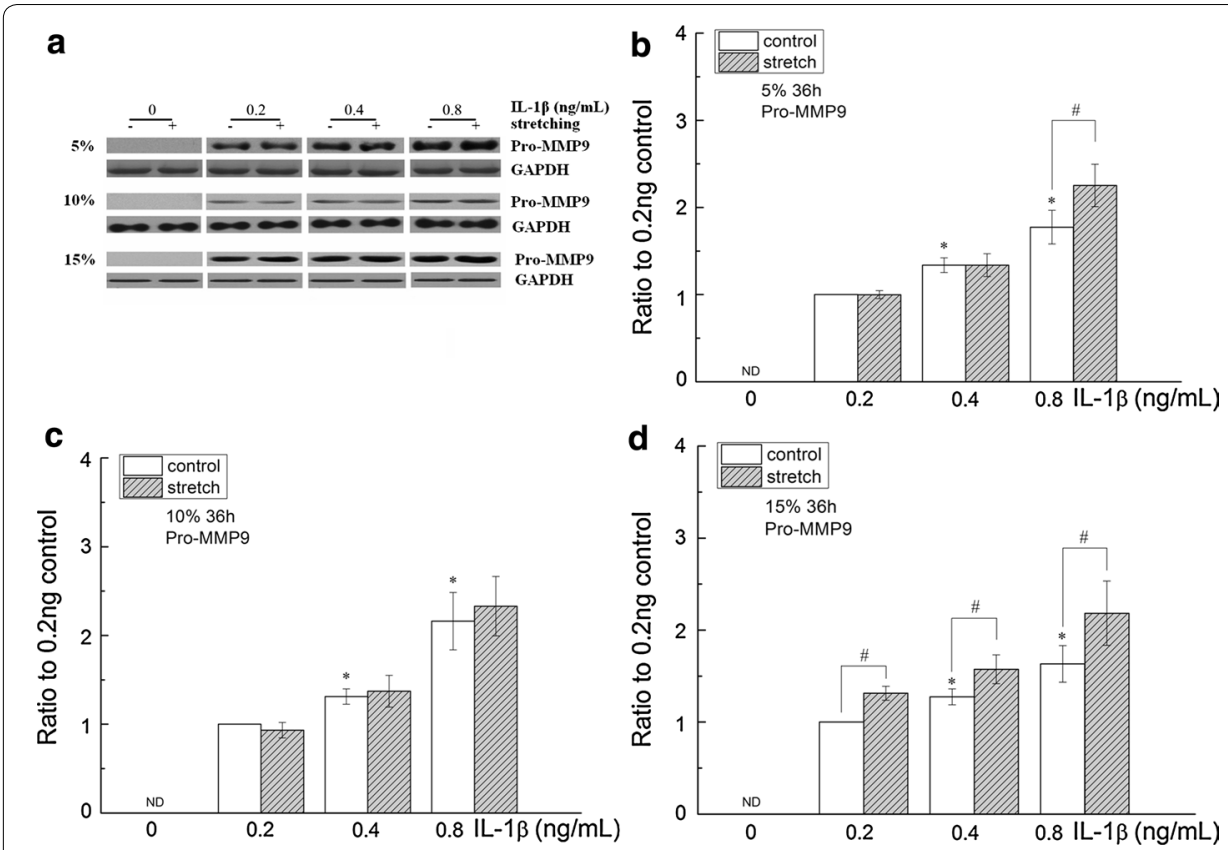

Fig. 5 The effects of cyclic stretching and IL-1 $\beta$ on MMP9 activity in corneal fibroblasts. MMP9 was detected by western blot (a) and quantified by densitometry $(\mathbf{b}-\mathbf{d})$. The indicated quantitative data are the mean of three different experiments $(n=6)$. ND, not detected; ${ }^{*} p<0.05$, ratio compared to $0.2 \mathrm{ng} / \mathrm{mL} \mathrm{IL}-1 \beta ;{ }^{\#} p<0.05$, compared with the static control at the same IL-1 $\beta$ treatment

$0.8 \mathrm{ng} / \mathrm{mL} \mathrm{IL}-1 \beta$ treatment $)$ and the $5 \%$ stretching group $(0.8 \mathrm{ng} / \mathrm{mL} \mathrm{IL-} 1 \beta$ treatment). By contrast, this upregulation was not observed in all of the $10 \%$ stretching groups.

All of the aforementioned results were highly concordant between gelatin zymography and western blot analyses.

\section{Discussion}

Corneal fibroblasts experience complex mechanical strains with myriad amplitudes and frequencies after keratorefractive surgery. We attempted to duplicate the conditions of the physical and chemical environments of corneal fibroblasts in the post-refractive surgery cornea or the cornea under high IOP conditions (such as abnormal eye rubbing) to understand the effects of various types of mechanical stimulation on ECM synthesis. The parameters used in this experiment were 5,10 and $15 \%$ biaxial stretching at $0.1 \mathrm{~Hz}$ maintained for $36 \mathrm{~h}$, which have been used by other investigators using other cell types $[17,35,36]$. If the cornea is treated as a simple pressure vessel, then the strain across the cornea will be directly proportional to IOP and inversely proportional to the modulus and thickness of the cornea [3,37]. Notably, the 5,10 and $15 \%$ strain used in our experiments could emulate the effect of the increase in IOP or the decrease in the modulus and thickness of the cornea.

In the absence of IL-1 $\beta, 5 \%$ stretching decreased the expression of Pro-MMP2, whereas 10 and $15 \%$ stretching increased the expression of Pro-MMP2; similar results have been observed in human patellar tendon fibroblasts [38]. The major finding of this study is that cyclic equibiaxial stretching did not change the cell orientation but changed the cell morphology by increase the contractility of F-actin fibres. IL- $1 \beta$ alone induced 
the expression of Pro-MMP9 and increased the expression of Pro-MMP2, which were further enhanced by $15 \%$ stretching or 5 and $10 \%$ stretching, respectively; In the presence of IL- $1 \beta$, rabbit corneal fibroblasts exhibited different responses to the distinctive strain patterns. All of these findings, together with the findings of this study, indicate that IL-1 $\beta$ combined with mechanical strain may lead to tissue destruction under some conditions.

Mechanical stretching has been shown to regulate MMPs in other types of ocular cells $[17,26,27,29]$. A $15 \%$ cyclic equibiaxial stretching resulted in a significant increase in Pro-MMP2 after 12 and $48 \mathrm{~h}$ and significantly increased the production of the active form of MMP2 after $48 \mathrm{~h}$. Increased levels of active MMP2 in the sclera would be expected to contribute to scleral ECM degradation, scleral thinning and possible ocular ectasia [17]. In this study, $15 \%$ cyclic stretching and IL-1 $\beta$ had no synergistic effect on the protein level of MMP2. This finding may be due to the following reasons. First, unlike MMP9, which was undetectable in the absence of IL-1 $\beta$, MMP2 was constitutively produced by corneal fibroblasts at a level that can be easily visualised by zymography or Western blot [39]. This finding indicated that MMP2 may serve a daily surveillance function [40] and be involved in long-term regulation during the corneal ECM remodelling process, as other researchers have indicated [41]. Second, IL-1 $\beta$ combined with cyclic stretching may alter the pattern of MMP expression by the corneal fibroblasts.

Type IV collagen and type V collagen are distributed in the basement membrane of the corneal epithelium and the corneal stroma, which provide the majority of the tensile strength of the cornea [7]. The destruction of collagen fibrils will lead to corneal thinning and abnormalities in the structure of the cornea and weaken the biomechanical strength of the cornea. This study has shown that the combination of IL-1 $\beta$ and cyclic stretching (5 and $10 \%$ ) increases MMP2 expression and that $15 \%$ stretching amplifies IL- $1 \beta$ induced MMP9. These MMPs are directly involved in collagen degradation, which may explain why high distending forces located on the thinner or weakened cone apex (e.g., forceful eye rubbing) tend to promote the development or progression of some forms of post-refractive surgery keratectasia, particularly with inflammation.

Living connective tissue is designed to combat mechanical stress without failing. However, corneal repair mechanisms may be different from those in other tissues with functions that depend on form and strength but not transparency [42]. Several studies have shown that overload induces MMPs and participates in ECM degradation [17]. Notably, static and dynamic fatigue processes, particularly dynamic fatigue, hasten mechanical failure and enzymatic proteolysis occurs more rapidly in bovine pericardium subjected to fatigue [43]. The development of post-refractive surgery keratectasia is a complicated and multifactorial process, and the studies on the effects of mechanical stretching and inflammatory mediators on corneal fibroblasts are likely simplistic approximations of the dynamic environment in which corneal fibroblasts reside. However, the present study demonstrates that corneal fibroblasts can respond to mechanical load and that tensile stress can amplify IL-1 $\beta$-induced MMP expression. Corneal stromal cells reside within a complex 3-D matrix in vivo, and MMPs play an important role in mediating corneal stromal cell spreading, migration [44], and ECM remodelling [33] within the 3-D collagen matrix. The potential effects of mechanical stretching on the expression of MMPs by corneal stromal cells in 3-D matrix remodelling should be investigated further. 


\section{Conclusions}

Corneal fibroblasts were subjected to combined cyclic stretching and IL-1 $\beta$ to determine the effect of mechanical strain on corneal ECM metabolism. The activities of MMP2 and MMP9 were evaluated. The results of the experiment indicated that a low stretching magnitude (5 \%) can reduce corneal ECM degradation, whereas large stretching magnitudes (10 and $15 \%)$ can increase the degradation of the corneal ECM in the absence of IL-1 $\beta$. IL-1 $\beta$ alone induced the expression of Pro-MMP9 and increased the expression of Pro-MMP2. In the presence of IL-1 $\beta$, the expression of MMPs was further enhanced by mechanical stretching, and the increased MMPs would be expected to participate in the corneal ECM remodelling, ultimately leading to post-refractive surgery keratectasia. The study confirmed the hypothesis that mechanical stretching together with IL-1 $\beta$ participate in MMP regulation and ECM remodelling in corneal fibroblasts, which indicate the importance of controlling the inflammatory response and avoiding the eye rubbing activity following a corneal refractive surgery procedure.

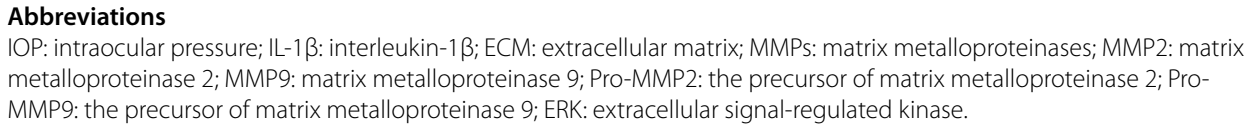

\section{Authors' contributions}

$\mathrm{XL}$ and WC participated in the design of the study; PF carried out the experiments and drafted the manuscript; $X \mathrm{~L}$ and $\mathrm{CL}$ contributed in analysis of results and preparation of the figures; SR and XW checked the grammar and spelling, helped to draft the manuscript; GD performed the statistical analysis; XL provided some detailed guidance on the revised manuscript and additional experiments. All authors have read and approved the final manuscript.

\section{Author details}

${ }^{1}$ Institute of Applied Mechanics and Biomedical Engineering, Taiyuan University of Technology, Taiyuan 030024, China.

${ }^{2}$ College of Mechanics, Taiyuan University of Technology, Taiyuan 030024, China. ${ }^{3}$ Biology Department, Taiyuan Normal University, Jinzhong 030619, China.

\section{Acknowledgements}

This study was supported by Grants from the National Nature Science Foundation of China $(31271005,11402161$ and 11402162) and the Natural Science Foundation of Shanxi Province (2012011046-2).

\section{Competing interests}

The authors declare that they have no competing interests.

\section{Ethical approval}

The study was approved by the Animal Care and Use Committee of the Shanxi Science and Technology Department.

Received: 3 February 2016 Accepted: 1 June 2016

Published online: 10 June 2016

\section{References}

1. Spadea L, Cantera E, Cortes M, Conocchia NE, Stewart CW. Corneal ectasia after myopic laser in situ keratomileusis: a long-term study. Clin Ophthalmol. 2012;6:1801-13.

2. Avetisov SE, Bubnova IA, Novikov IA, Antonov AA, Siplivyi VI. Experimental study on the mechanical strain of corneal collagen. J Biomech. 2013;46:1648-54.

3. Pierścionek BK, Asejczyk-Widlicka M, Schachar RA. The effect of changing intraocular pressure on the corneal and scleral curvatures in the fresh porcine eye. Brit J Ophthalmol. 2007;91:801-3.

4. Qazi MA, Sanderson JP, Mahmoud AM, Yoon EY, Roberts CJ, Pepose JS. Postoperative changes in intraocular pressure and corneal biomechanical metrics: laser in situ keratomileusis versus laser-assisted subepithelial keratectomy. J Cataract Refract Surg. 2009;35:1774-88.

5. Gefen A, Shalom R, Elad D, Mandel Y. Biomechanical analysis of the keratoconic cornea. J. Mech Behav Biomed. 2009;2:224-36.

6. Pandolfi A, Fotia G, Manganiello F. Finite element simulations of laser refractive corneal surgery. Chin J. Mech Engen. 2009:25:15-24

7. Dupps WJ, Wilson SE. Biomechanics and wound healing in the cornea. Exp Eye Res. 2006;83:709-20.

8. Caprioli J, Coleman AL. Blood pressure, perfusion pressure, and glaucoma. Am J Ophthalmol. 2010;149(5):704-12. 
9. Buys YM, Alasbali T, Jin YP, et al. Effect of sleeping in a head-up position on intraocular pressure in patients with glaucoma. Ophthalmology. 2010;117:1348-51.

10. Lee TE, Yoo C, Kim YY. Effects of different sleeping postures on intraocular pressure and ocular perfusion pressure in healthy young subjects. Ophthalmology. 2013;120:1565-70.

11. McMonnies CW. Management of chronic habits of abnormal eye rubbing. Contact Lens Anterio. 2008;31:95-102.

12. Wilson SE, Mohan RR, Mohan RR, Ambrósio R, Hong J, Lee J. The corneal wound healing response: cytokine-mediated interaction of the epithelium, stroma, and inflammatory cells. Prog Retin Eye Res. 2001;20:625-37.

13. Wilson SE, Esposito A. Focus on molecules: interleukin-1: a master regulator of the corneal response to injury. Exp Eye Res. 2009;89:124-5.

14. Luo L, Li DQ, Doshi A, Farley W, Corrales RM, Pflugfelder SC. Experimental dry eye stimulates production of inflammation cytokines and MMP-9 and activates MAPK signaling pathways on the ocular surface. Invest Ophthalmol Vis Sci. 2004;45:4293-301.

15. Stern ME, Pflugfelder SC. Inflammation in Dry Eye. Ocul Surf. 2004;2:124-30.

16. Toda I. LASIK and dry eye. Compr Ophthalmol Update. 2006;8:79-85 (discussion 87-9)

17. Shelton L, Rada JS. Effects of cyclic mechanical stretch on extracellular matrix synthesis by human scleral fibroblasts. Exp Eye Res. 2007;84(2):314-22.

18. Li DQ, Lokeshwar BL, Solomon A, et al. Regulation of MMP-9 production by human corneal epithelial cells. Exp Eye Res. 2001;73(4):449-59.

19. Maguen E, Zorapapel NC, Zieske JD, Ninomiya Y, Sado Y, Kenney MC, et al. Extracellular matrix and matrix metalloproteinase changes in human corneas after complicated laser-assisted in situ keratomileusis (LASIK). Cornea. 2002;21:95-100.

20. Mulholland B, Tuft SJ, Khaw PT. Matrix metalloproteinase distribution during early corneal wound healing. Eye. 2005;19:584-8.

21. Xue ML, Wakefield D, Willcox MD, Lloyd AR, Di GN, Cole N, et al. Regulation of MMPs and TIMPs by IL-1 beta during corneal ulceration and infection. Invest Ophthalmol Vis Sci. 2003;44:2020-5.

22. Esquenazi S, Esquenazi I, Grunstein L, He J, Bazan H. Immunohistological evaluation of the healing response at the flap interface in patients with LASIK ectasia requiring penetrating keratoplasty. J Refract Surg. 2009;25:739-46.

23. Maguen E, Maguen B, Regev L, Ljubimov AV. Immunohistochemical evaluation of two corneal buttons with postLASIK keratectasia. Cornea. 2007;26:983-91.

24. Maguen E, Rabinowitz YS, Regev L, Saghizadeh M, Sasaki T, Ljubimov AV. Alterations of extracellular matrix components and proteinases in human corneal buttons with INTACS for post-laser in situ keratomileusis keratectasia and keratoconus. Cornea. 2008;27:565-73.

25. Wang JH, Thampatty BP. An introductory review of cell mechanobiology. Biomech Model Mechan. 2006:5:1-16.

26. Cui W, Bryant MR, Sweet PM, McDonnell PJ. Changes in gene expression in response to mechanical strain in human scleral fibroblasts. Exp Eye Res. 2004;78:275-84.

27. Fujikura H, Seko Y, Tokoro T, Mochizuki M, Shimokawa H. Involvement of mechanical stretch in the gelatinolytic activity of the fibrous sclera of chicks, in vitro. Jpn J Ophthalmol. 2002;46:24-30.

28. Bradley JM, Kelley MJ, Rose A, Acott TS. Signaling pathways used in trabecular matrix metalloproteinase response to mechanical stretch. Invest Ophthalmol Vis Sci. 2003;44:5174-81.

29. Kirwan RP, Crean JK, Fenerty CH, Clark AF, O'Brien CJ. Effect of cyclical mechanical stretch and exogenous transforming growth factor- $\beta 1$ on matrix metalloproteinase- 2 activity in lamina cribrosa cells from the human optic nerve head. J Glaucoma. 2004;13:327-34.

30. Petroll WM, Vishwanath M, Ma L. Corneal fibroblasts respond rapidly to changes in local mechanical stress. Invest Ophthalmol Vis Sci. 2004:45:3466-74.

31. Wang JH, Thampatty BP, Lin JS, Im HJ. Mechanoregulation of gene expression in fibroblasts. Gene. 2007;391:1-15.

32. Liu C, Feng P, Li X, et al. Expression of MMP-2, MT1-MMP, and TIMP-2 by cultured rabbit corneal fibroblasts under mechanical stretch. Exp Biol Med. 2014;239:907-12.

33. LuY, Fukuda K, Liu Y, Kumagai N, Nishida T. Dexamethasone inhibition of IL-1-induced collagen degradation by corneal fibroblasts in three-dimensional culture. Invest Ophthalmol Vis Sci. 2004;45:2998-3004.

34. Sobrin L, Liu Z, Monroy DC, et al. Regulation of MMP-9 activity in human tear fluid and corneal epithelial culture supernatant. Invest Ophthalmol Vis Sci. 2000;41(7):1703-9.

35. Archambault J, Tsuzaki $M$, Herzog W, et al. Stretch and interleukin-1 $\beta$ induce matrix metalloproteinases in rabbit tendon cells in vitro. J Orthop Res. 2002;20(1):36-9.

36. Oya K, Sakamoto N, Ohashi T, et al. Combined stimulation with cyclic stretching and hypoxia increases production of matrix metalloproteinase-9 and cytokines by macrophages. Biochem Bioph Res Co. 2011;412(4):678-82.

37. Asejczyk-Widlicka M, Śródka W, Schachar RA, Pierścionek BK. Material properties of the cornea and sclera: a modelling approach to test experimental analysis. J Biomech. 2011;44:543-6.

38. Nakayasu K, Tanaka M, Konomi H, Hayashi T. Distribution of types I, II, III, IV and V collagen in normal and keratoconus corneas. Ophthalmic Res. 1986;18:10-1.

39. Girard MT, Matsubara M, Fini ME. Transforming growth factor- $\beta$ and Interleukin-1 modulate metalloproteinase expression by corneal stromal cells. Invest Ophthalmol Vis Sci. 1991;32:2441-54.

40. Fini ME, Girard MT. Expression of collagenolytic/gelatinolytic metalloproteinases by normal cornea. Invest Ophthalmol Vis Sci. 1990;31:1779-88.

41. Matsubara M, Girard MT, Kublin CL, Cintron C, Fini ME. Differential roles for two gelatinolytic enzymes of the matrix metalloproteinase family in the remodelling cornea. Dev Biol. 1991;147:425-39.

42. Comaish IF, Lawless MA. Progressive post-LASIK keratectasia biomechanical instability or chronic disease process. J Cataract Refract Surg. 2002;28:2206-13.

43. Ellsmere JC, Khanna RA, Lee JM. Mechanical loading of bovine pericardium accelerates enzymatic degradation. Biomaterials. 1999;20:1143-50.

44. Zhou H, Kimura K, Orita T, Nishida T, Sonoda KH. Inhibition by medroxyprogesterone acetate of interleukin-1 $\beta$ induced collagen degradation by corneal fibroblasts. Invest Ophthalmol Vis Sci. 2012;53:4213-9. 